\title{
Comparison of the shock index, modified shock index, and age shock index in adult admissions to a tertiary hospital
}

\author{
David Sotello MD, Shengping Yang PhD, Kenneth Nugent MD
}

\begin{abstract}
Background: Multiple variables interact constantly to maintain the hemodynamic status of patients. The shock index (SI), the modified shock index (MSI), and the age shock index (ASI) have been studied in different clinical settings to predict hemodynamic instability and associated outcomes. These indices are calculated from simple hemodynamic parameters, are non-invasive, and represent no additional expense. We wanted to analyze the performance of these three different indices in the patients admitted to our hospital.

Methods: We performed a retrospective study in which we identified all adult patients (>18 years, <89 years) admitted to the University Medical Center in Lubbock, Texas, from 10/01/2015 until 9/30/2016. We collected basic clinical information, including age, initial blood pressure measurements, discharge diagnoses, length of stay (LOS), and mortality. With these variables we calculated for each patient the admission SI (defined as heart ratel systolic blood pressure), MSI (heart rate/mean arterial pressure), and ASI (age $\times S I$ ). We separated the patients according to their admission diagnoses and calculated the median and $25^{\text {th }}-75^{\text {th }}$ percentiles for those parameters. We also compared mortality and LOS based on their admission SI using two different cutoff points at 0.7 and 1.0, their admission MSI (cutoff: 1.3), and their ASI (cutoff: 50).

Results: A total of 18,478 adult patients admitted to our institution were included in this study. The median age was 53 years, the median LOS was 4 days, and the overall mortality was $3.8 \%$. The median SI was $0.67 ; 43.3 \%$ of patients had an SI $>0.7$ and $8.11 \%$ had an $S I>1.0$. The median SI calculated for the patients with sepsis was 0.88; this was higher than the rest of admission diagnoses $(p<0.001)$. The mortality of the patients with an $\mathrm{SI}>0.7$ was $5.1 \%$ and with $S I>1.0$ was $11.3 \%(p<0.001)$. When comparing the MSI, those with an MSI $>1.3$ had a mortality of $10.3 \%$, and those with an $A S I>50$ had a mortality of $10.0 \%(p<0.001)$.

Conclusions: The SI, MSI, and ASI are non-invasive calculations that may provide useful information when triaging patients early during admission. The diagnosis of sepsis results in a higher median SI, which may represent better prediction in outcomes compared with the rest of admission diagnoses. In our study, the three indexes performed equally. Since the SI with a cut-off of 1.0 identified patients with higher mortality risk, we would recommend using this cut-off instead of 0.7 .
\end{abstract}

Keywords: shock index, age shock index, modified shock index, outcomes

Corresponding author: David Sotello

Contact Information: David.sotello@ttuhscc.edu

DOI: $10.12746 /$ swrccc.v7i28.539 


\section{INTRODUCTION}

The initial evaluation of patients is crucial for effective management and good outcomes. Clinicians routinely have to deal with difficult decisions when managing unstable patients. Finding a useful and consistent tool that will help triage patients regarding hemodynamic instability is fundamental, and equally important is a tool that provides critical information about outcomes. For these reasons the shock index (SI) was defined and implemented more than 50 years ago as an initial tool to assess hemodynamic instability. ${ }^{1}$ It has been studied with different cutoff points, and more recently a modified SI (MSI) and age $\mathrm{SI}(\mathrm{ASI})$ have been proposed as better alternatives to the original tool for triaging as well as for predicting patient outcomes. For these reasons, we wanted to evaluate the performance of these very convenient and easy to calculate tools in our patient population at University Medical Center, Lubbock, Texas.

\section{Methods}

This is a retrospective study; it included all adult ( $\geq 18$ years old) admitted to University Medical Center in Lubbock, Texas, between 10/01/2015 and 09/30/2016. Patients less than 18 years of age and $>89$ years of age were excluded. General demographic information was collected, including age, gender, the initial blood pressure and heart rate, diagnoses based on ICD-10 discharge coding, length of stay (LOS), and mortality. University Medical Center is a 494-bed tertiary referral center in West Texas.

The patients were organized according to main admission diagnoses, with their respective median and $25^{\text {th }}$ and $75^{\text {th }}$ percentiles calculated for admission heart rate, systolic blood pressure, and SI. The admission SI, MSI and ASI were calculated for each patient. To make these calculations, the following formulas were used: SI (defined as heart rate/systolic blood pressure), MSI (defined as heart rate/mean arterial pressure), and ASI (age $\times \mathrm{SI}$ ). The patients were later separated into two groups: those with an $\mathrm{SI}>0.7$ and those with an $\mathrm{SI}>1$, since these are the two most commonly used threshold points. ${ }^{2,3}$ For the two groups of patients divided by the thresholds (i.e., SI $>0.7$ and 1 , respectively), mortality and LOS were calculated. The patients were also separated according to their MSI, using a threshold of 1.3 and according to their corresponding ASI using a threshold of $50 ;{ }^{4}$ for each of these groups their respective mortality and LOS were calculated.

A descriptive analysis was reported by using the median $\left(25^{\text {th }}, 75^{\text {th }}\right.$ percentiles $)$. Comparisons among groups were made using the Chi-square test. Pair-wise comparisons were made only when the overall testing was significant. All analyses were performed using the SAS (Windows version 9.3; SAS Institute, Cary, NC) and the $R$ software (R Core team; 2018). $P$ values less than 0.05 were considered statistically significant.

\section{RESULTS}

A total of 18,478 patients were included in this study. The median age was 53 years $\left(25^{\text {th }}-75^{\text {th }}\right.$ percentiles: 33-67 years). The main admission diagnoses are listed in Table 1. The most common admission diagnoses were sepsis, pneumonia, and ischemic heart disease. The median LOS was 4 days $\left(25^{\text {th }}-75^{\text {th }}\right.$ percentiles: $2-6$ days). The overall mortality was $3.8 \%$.

The median heart rate was 88 beats per minute $\left(25^{\text {th }}-75^{\text {th }}\right.$ percentiles: $75-102$ beats per minute). The median systolic blood pressure was $131 \mathrm{~mm}$ HG $\left(25^{\text {th }}-75^{\text {th }}\right.$ percentiles:116-148 $\left.\mathrm{mm} \mathrm{Hg}\right)$. The median SI was $0.67\left(25^{\text {th }}-75^{\text {th }}\right.$ percentiles: $\left.0.55-0.81\right)$. The SI was highest for the diagnosis of sepsis when compared to other diagnoses $(p<0.001$, Table 1$)$.

After separating the patients according to the most commonly used SI thresholds (i.e., $>0.7$ vs $>1$ ), a total of 8,009 patients $(43.43 \%)$ had an $\mathrm{SI}>0.7$ and 1,495 patients $(8.11 \%)$ had an $\mathrm{SI}>1$. The most common diagnosis with an SI either $>0.7$ or $>1$ was sepsis, with $78.43 \%$ and $29.82 \%$ of patients in this category, respectively.

We compared the LOS and hospital mortality in the patients using a threshold of 0.7 ; the mortality with an $\mathrm{SI}<0.7$ was $2.7 \%$ and with an $\mathrm{SI}>0.7$ was $5.1 \%$. We also separated the patients using an SI threshold 
Table 1. Shock index by disease

\begin{tabular}{|c|c|c|c|}
\hline Category & $\begin{array}{c}\text { Heart Rate } \\
\text { Median }\left(25^{\text {th }}, 75^{\text {th }}\right) \\
\end{array}$ & $\begin{array}{c}\text { Systolic BP } \\
\text { Median }\left(25^{\text {th }}, 7^{\text {th }}\right) \\
\end{array}$ & $\begin{array}{c}\text { Shock Index } \\
\text { Median }\left(25^{\text {th }}, 75^{\text {th }}\right) \\
\end{array}$ \\
\hline All patients & $88(75,102)$ & $131(116,148)$ & $0.67(0.55,0.81)$ \\
\hline $\begin{array}{l}\text { Sepsis } \\
(\mathrm{A} 41.01, \mathrm{~A} 41.51, \mathrm{~A} 41.9)\end{array}$ & $106(92,119)$ & $120(102,141)$ & $0.88(0.72,1.05)$ \\
\hline $\begin{array}{l}\text { Pneumonia } \\
(\mathrm{J} 18.9)\end{array}$ & $94(82,108)$ & $133(115.5,152)$ & $0.72(0.59,0.85)$ \\
\hline $\begin{array}{l}\text { COPD } \\
(\mathrm{J} 44.1)\end{array}$ & $97(83.5,110)$ & $141(125,155)$ & $0.69(0.59,0.80)$ \\
\hline $\begin{array}{l}\text { Acute kidney failure } \\
\text { (N17.9) }\end{array}$ & $83(72,94.5)$ & $122(105,144)$ & $0.69(0.55,0.84)$ \\
\hline $\begin{array}{l}\text { Urinary tract infection } \\
\text { (N39.0) }\end{array}$ & $87(73,98)$ & $132(113,151)$ & $0.64(0.53,0.77)$ \\
\hline $\begin{array}{l}\text { Other diseases of digestive system } \\
(\mathrm{K} 92.0, \mathrm{~K} 92.1, \mathrm{~K} 92.2)\end{array}$ & $90(77,104.75)$ & $121.5(106,139.75)$ & $0.71(0.60,0.91)$ \\
\hline $\begin{array}{l}\text { Ischemic heart diseases } \\
\text { (I20-I25) }\end{array}$ & $76(66,89)$ & $139(123,158)$ & $0.54(0.46,0.67)$ \\
\hline $\begin{array}{l}\text { Acute heart failure } \\
(\mathrm{I} 50.23, \mathrm{I} 50.33, \mathrm{I} 50.43, \mathrm{I} 50.9)\end{array}$ & $87(72,102)$ & $136(115,159)$ & $0.63(0.52,0.78)$ \\
\hline $\begin{array}{l}\text { Pancreatitis } \\
(\mathrm{K} 85.1, \mathrm{~K} 85.9)\end{array}$ & $87(75,97)$ & $137(120,157)$ & $0.61(0.52,0.73)$ \\
\hline $\begin{array}{l}\text { Acute respiratory failure } \\
(\mathrm{J} 96.00, \mathrm{~J} 96.01, \mathrm{~J} 96.21, \mathrm{~J} 96.22)\end{array}$ & $91.5(77,108)$ & $131(110,149.75)$ & $0.70(0.58,0.84)$ \\
\hline $\begin{array}{l}\text { Type II diabetes } \\
\text { (E11) }\end{array}$ & $88(78,100)$ & $145(123.25,163.75)$ & $0.60(0.51,0.72)$ \\
\hline $\begin{array}{l}\text { Type I diabetes } \\
\text { (E10) }\end{array}$ & $105(95,118.5)$ & $128(116.5,143)$ & $0.82(0.67,0.96)$ \\
\hline
\end{tabular}

of 1 ; the mortality in patients with an $\mathrm{SI}<1$ was $3.1 \%$ and with an $\mathrm{SI}>1$ was $11.3 \%(p<0.001)$. The LOS did not vary when separating the patients with either SI threshold (Table 2).

The patients were also classified according to their calculated MSI and ASI. The observed mortality of patients with an $\mathrm{MSI} \leq 1.3$ was $2.9 \%$; the mortality of those with an MSI $>1.3$ was $10.3 \%(p<0.001)$. Patients with an ASI $\leq 50$ had a mortality of $2.5 \%$; those with an ASI $>50$ that had a mortality of $10.0 \%$ $(p<0.001)$. The median LOS for patients with ASI $\leq$ 50 was 3 days $\left(25^{\text {th }}-75^{\text {th }}\right.$ percentiles: $2-6$ days $)$, and for patients with an ASI $>50$ the median was 5 days $\left(25^{\text {th }}-75^{\text {th }}\right.$ percentiles; $3-8$ days, $p<0.001$, Table 3$)$.

\section{Discussion}

The SI has been widely used in different clinical settings for assessment of hemodynamic instability and prediction or estimation of outcomes. It was first introduced in 1967 and has proven to be more sensitive than either heart rate or systolic blood pressure to detect hemodynamic compromise. ${ }^{1,2}$ The SI represents a very convenient noninvasive tool to aide in 
Table 2. Mortality and length of stay according to calculated shock index

\begin{tabular}{|l|c|c|c|}
\hline & $\begin{array}{c}\text { Alive before discharge } \\
\mathbf{n}(\mathbf{\%})\end{array}$ & $\begin{array}{c}\text { Expired in hospital } \\
\mathbf{n}(\mathbf{\%})\end{array}$ & $\begin{array}{c}\text { Length of stay } \\
\text { median } \mathbf{( 2 5}^{\text {th }} \mathbf{7 5}^{\text {th }} \mathbf{)}\end{array}$ \\
\hline Shock Index $\leq \mathbf{0 . 7}$ & $10153(97.3)$ & $280(2.7)$ & $4(2,6)$ \\
\hline Shock Index $>\mathbf{0 . 7}$ & $7598(94.9)$ & $411(5.1)$ & $4(2,7)$ \\
\hline Shock Index $\leq \mathbf{1}$ & $16425(96.9)$ & $522(3.1)$ & $4(2,6)$ \\
\hline Shock Index $>\mathbf{1}$ & $1326(88.7)$ & $169(11.3)$ & $4(3,9)$ \\
\hline
\end{tabular}

The $\mathrm{p}$ values for comparing both mortality and length of stay between the above and below cut-off groups are $<0.001$.

the assessment of potentially unstable patients, with the advantage that is very easy to calculate and represents no additional expense to patients.

The normal SI was originally determined to be in the range of 0.5 to $0.7,2,5$ but different thresholds have also been used, e.g., 0.9, 1.0 or higher. ${ }^{6} \mathrm{~A}$ higher $\mathrm{SI}$ cutoff loses sensitivity and gains specificity; for this reason, some have proposed that a cutoff point of 1.0 might represent a reasonable balance between specificity vs. sensitivity with the advantage of providing more impact in its ability to predict mortality. ${ }^{3}$

The SI has been applied in different clinical settings. It was originally used as an early evaluation of the circulatory status in patients with trauma and suspected hypovolemic shock. ${ }^{1}$ Since then, it has been applied in other areas; Zhang et al reported that an elevated $\mathrm{SI}(>0.7)$ was associated with increased in-hospital mortality and worse short and long term outcomes in patients with acute myocardial infarction. ${ }^{7}$ Rassameehiran et al demonstrated that the SI might be a useful tool to identify patients with acute upper gastrointestinal bleeding (UGIB) who may have adverse short-term outcomes. It was comparable to other risk-scoring tools for UGIB and may have a potential use as a risk-stratification tool in UGIB. ${ }^{2}$ Balhara et al determined that an elevated SI (>1.2) might predict hospital admission and inpatient mortality when used in the emergency room as a triage tool. ${ }^{6}$ McCall et al studied the use of the SI in patients with patients with stroke and found that elevated SI values may predict stroke mortality, especially when determining early mortality (3-day). ${ }^{8}$ Nathan et al investigated the impact of an elevated $\mathrm{SI}$ in postpartum hemorrhage and found that an elevated $\mathrm{SI}(>0.9)$ had good sensitivity for predicting ICU admission and a SI $\geq 1.7$ identified patients requiring an urgent intervention (e.g., emergency caesarean section). ${ }^{9}$ Finally, Tseng and Nugent did in an extensive literature review of $\mathrm{SI}$ in patients with sepsis and found that an elevated SI is useful in the evaluation of fluid resuscitation and in the identification of patients with lactic acidosis, organ failure and increased mortality. ${ }^{5}$

Table 3. Mortality and length of stay according to modified shock index and age shock index

\begin{tabular}{|l|c|c|c|}
\hline & $\begin{array}{c}\text { Alive before discharge } \\
\mathbf{n}(\mathbf{\%})\end{array}$ & $\begin{array}{c}\text { Expired in hospital } \\
\mathbf{n}(\mathbf{\%})\end{array}$ & $\begin{array}{c}\text { Length of stay } \\
\left.\text { median } \mathbf{( 2 5}^{\text {th }} \mathbf{\mathbf { 7 5 } ^ { \text { th } }}\right)\end{array}$ \\
\hline Shock Index $\leq \mathbf{1 . 3 *}$ & $15938(97.1)$ & $482(2.9)$ & $4(2,6)$ \\
\hline Shock Index $>\mathbf{1 . 3}$ & $1798(89.7)$ & $206(10.3)$ & $4(3,8)$ \\
\hline Shock Index $\leq \mathbf{5 0 * *}$ & $14928(97.5)$ & $376(2.5)$ & $3(2,6)$ \\
\hline Shock Index $>\mathbf{5 0}$ & $2823(90.0)$ & $315(10.0)$ & $5(3,8)$ \\
\hline
\end{tabular}

*Modified shock index; ** Age shock index.

The $\mathrm{p}$ values for comparing both mortality and length of stay between the above and below cut-off for both groups are $<0.001$. 
Several authors have compared the performance of SI versus $\mathrm{MSI}$ and $\mathrm{ASI}$ to identify the most convenient tool to estimate hemodynamic instability. Yu et al found that ASI may be able to better identify patients at high-risk of death in acute myocardial infarction when compared with SI and MSI. ${ }^{10}$ Zarzaur et al found that $\mathrm{SI}$ and $\mathrm{ASI}$ performed equally when estimating 48-hour mortality in trauma patients secondary to blunt injury, but ASI was superior for patients older than 55 years of age. ${ }^{11}$ Terceros-Almanza et al found that SI and MSI performed equally as predictors of massive hemorrhage. ${ }^{12}$ Liu et al found that MSI performed better than either SI or heart rate and blood pressure alone in predicting mortality in emergency patients. ${ }^{13}$ Torabi et al compared SI, MSI, and ASI for prediction of mortality in emergency patients and found that ASI performed better than $\mathrm{SI}$ and $\mathrm{MSI}^{14}$ Similar results were obtained by Kim et al when they compared the three scores in geriatric trauma patients in the emergency department. ${ }^{4}$ In our study the three scores performed equally in predicting inpatient mortality, with the advantage of ASI being able to predict longer hospital LOS than the SI and MSI.

Our study has several limitations. It is a retrospective study; the results were based on hospital discharge coding and were not independently verified through chart review. Second, we were not able to analyze the causes of mortality in these patients. Third, we only calculated SI, MSI, and ASI at the patient's admission and did not follow it throughout the hospitalization.

\section{Conclusions}

The SI, modified SI, and age SI are convenient tools to help in the assessment of hemodynamic instability of patients; these tools are helpful in different clinical scenarios, including trauma, obstetrics, emergency medicine, gastroenterology, intensive care, sepsis, stroke, etc. Besides helping in the initial evaluation of patients, they may also provide important information in the estimation of outcomes, such as mortality and LOS. We recommend the use of SI threshold of 1 instead of 0.7 ; this seems to correlate better with the prediction of outcomes. Patients with sepsis have a higher calculated SI than patients with other diagnoses; serial measurement of the SI could provide additional information in the management of these patients. It might worthwhile to determine the best threshold value for patients with specific main diagnosis.

Article citation: Comparison of the shock index, modified shock index, and age shock index in adult admissions to a tertiary hospital. The Southwest Respiratory and Critical Care Chronicles 2019;7(28): 18-23

From: The Departments of Internal Medicine (DS, KN) at Texas Tech University Health Sciences Center in Lubbock, Texas; Department of Biostatistics (SY), Pennington Biomedical Research Center, Baton Rouge, LA

Submitted: $11 / 21 / 2018$

Accepted: $4 / 8 / 2019$

Reviewer: Camilo Pena MD

Conflicts of interest: none

This work is licensed under a Creative Commons Attribution-ShareAlike 4.0 International License.

\section{REFERENCES}

1. Allgöwer M, Burri C. Shock index. Dtsch Med Wochenschr 1967;92:1947-1950.

2. Rassameehiran S, Teerakanok J, Suchartlikitwong S, et al. Utility of the shock index for risk stratification in patients with acute upper gastrointestinal bleeding. South Med J 2017; 110:738-743.

3. Schroll R, Swift D, Tatum D, et al. Accuracy of shock index versus $A B C$ score to predict need for massive transfusion in trauma patients. Injury 2018 Jan;49(1):15-19.

4. Kim SY, Hong KJ, Shin SD, et al. Validation of the shock index, modified shock index, and age shock index for predicting mortality of geriatric trauma patients in emergency departments. J Korean Med Sci 2016;31:2026-2032.

5. Tseng J, Nugent K. Utility of the shock index in patients with sepsis. Am J Med Sci 2015 Jun;349(6):531-5.

6. Balhara KS, Hsieh YH, Hamade B, et al. Clinical metrics in emergency medicine: the shock index and the probability of hospital admission and inpatient mortality. Emerg Med J 2017;34:89-94.

7. Zhang $X$, Wang $Z$, Wang $Z$, et al. The prognostic value of shock index for the outcomes of acute myocardial infarction 
patients: A systematic review and meta-analysis. Medicine (Baltimore) 2017;96:e8014.

8. McCall SJ, Musgrave SD, Potter JF, et al. Clinical Network Evaluation Study (ASCNES) Group. The shock index predicts acute mortality outcomes in stroke. Int J Cardiol 2015;182:523-7.

9. Nathan HL, El Ayadi A, Hezelgrave NL, et al. Shock index: an effective predictor of outcome in postpartum haemorrhage?. BJOG 2015;122:268-75.

10. Yu T, Tian C, Song J, et al. Age shock index is superior to shock index and modified shock index for predicting longterm prognosis in acute myocardial infarction. Shock 2017; 48:545-550.
11. Zarzaur BL, Croce MA, Fischer PE, et al. New vitals after injury: shock index for the young and age $\mathrm{x}$ shock index for the old. J Surg Res 2008 Jun 15;147(2):229-36.

12. Terceros-Almanza LJ, García-Fuentes $C$, Bermejo-Aznárez $\mathrm{S}$, et al. Prediction of massive bleeding. Shock index and modified shock index. Med Intensiva 2017;41:532-538.

13. Liu YC, Liu JH, Fang ZA, et al. Modified shock index and mortality rate of emergency patients. World J Emerg Med 2012;3(2):114-7.

14. Torabi M, Moeinaddini S, Mirafzal A, et al. Shock index, modified shock index, and age shock index for prediction of mortality in Emergency Severity Index level 3. Am J Emerg Med 2016 Nov;34(11):2079-2083. 